\title{
A Conceptual Model for Effective Quality Management of Online and Blended Learning
}

\author{
Yves Blieck ${ }^{1}$, Chang Zhu ${ }^{1}$, Kim Schildkamp ${ }^{2}$, Katrien Struyven ${ }^{1,3}$, Bram Pynoo $^{1}$, Cindy L. \\ Poortman ${ }^{2}$ and Koen Depryck ${ }^{1}$ \\ ${ }^{1}$ Vrije Universiteit Brussel, Belguim \\ ${ }^{2}$ University of Twente, Netherlands \\ ${ }^{3}$ Hasselt University, Belguim \\ Yves.Blieck@Uhasselt.be \\ Chang.Zhu@vub.be \\ k.schildkamp@utwente.nl \\ katrien.struyven@uhasselt.be \\ Bram.Pynoo@vub.be \\ C.L.Poortman@utwente.nl \\ Koen.De.Pryck@vub.be \\ DOI: 10.34190/EJEL.20.18.2.007
}

\begin{abstract}
Institutions considering online and blended learning $(\mathrm{OBL})$ face the challenge of strategically adopting $O B L$ to develop, implement, monitor, assess and improve the quality of programmes and courses. The principles of continuous quality improvement (CQI) allow this challenge to be addressed. Effective CQI management implies that quality assurance and quality improvement follow and inform each other as part of a continuous cycle. Scholars report however, that quality management of OBL usually focuses on assurance. The purpose of this paper is to provide a state of the art approach for effective CQI management which allows practitioners to achieve coherence between quality assurance and improvement of OBL. In this conceptual paper we link and integrate work across fields to address the challenge of achieving coherence between quality assurance and improvement. We discuss research in the context of CQI that uncovers features of OBL that prevent practitioners from achieving coherence. The conceptual model for effective CQI of OBL integrates data based decision-making. The conceptual model provides a foundation for research on the effectiveness of this CQI management approach in the context of OBL. The quality management approach supports practitioners during the entire CQI-cycle to foster dialogue and consultation between all stakeholders in the institution in order to strategically develop assess and improve the quality of OBL programmes and courses. The originality of the model lies in making explicit data-based decision making as a driver for effective CQI management in the context of OBL.
\end{abstract}

Keywords: quality assurance, quality enhancement, quality improvement, e-learning, online and blended learning, databased decision making.

\section{Introduction}

Online and blended learning (OBL) is valued for its potential to remove barriers, such as accessibility and flexibility, that prevent students from participating in traditional education (Shea, 2007). Institutions face challenges when they (plan to) redesign their programmes in order to implement OBL (Jara and Mellar, 2009; Moskal, Dziuban and Hartman, 2013). Indeed, successful adoption, implementation and improvement of OBL requires that the needs of the different stakeholders in institutions are taken into account (Moskal, Dziuban and Hartman, 2013). This is important to ensure that the institution puts reliable and robust infrastructure and sufficient resources in place to support the faculty and the students during OBL (Moskal, Dziuban and Hartman, 2013). For instance, if it appears in the context of OBL that students do not receive sufficient support in an OBL programme, the institution must take actions to address this. This implies that professionals from the meso (the management) and micro level (the faculty responsible for courses/modules in a programme) enter into dialogue, consult the students, and decide what measures are appropriate (Deepwell, 2007; Ehlers, 2007).

Continuous quality improvement (COI) can facilitate a process of change, innovation, assessment and improvement and is suited to capture the perspectives of these different stakeholders (Becket and Brookes, 2005). CQI is defined as a quality '[...] management approach [...] to continuously improve the efficiency and effectiveness of all aspects of the organization's programmes and services in order to maximise benefits for clients. [...] relying on evidence-based information to support the organizations' success in achieving its goals and outcomes' (Sonpal-Valias, 2009, p.2). The implementation of a quality model is essential in CQI. 'A quality model defines the set of variables in terms of which quality is measured and the way in which it is measured' 
(Inglis, 2008, p.348). Figure 1 shows the 'variables' referred to in the literature as the quality areas (management, services and products) that capture the six common systemic quality dimensions that need to fit together' in institutions to achieve quality in OBL (Ossiannilsson et al., 2015). The traditional models for quality management of OBL adhere to this structure (Hansson, 2008; Marshall, 2010; Williams et al., 2012).

A quality model guides choices to improve and restructure management, services and programmes; and to evaluate an institutions' progress (Bloxham, 2010). In the example concerning insufficient support for student to use technology given above, adequate improvement measures might be increasing the support in using the technology in the dimension of 'support for students' (figure 1). However, improvement could also be achieved by measures in other quality dimensions. For example, adopting a more user friendly learning management system in the 'course delivery' dimension can also be an answer, provided of course that this dimension is present in the quality model implemented by the institution.

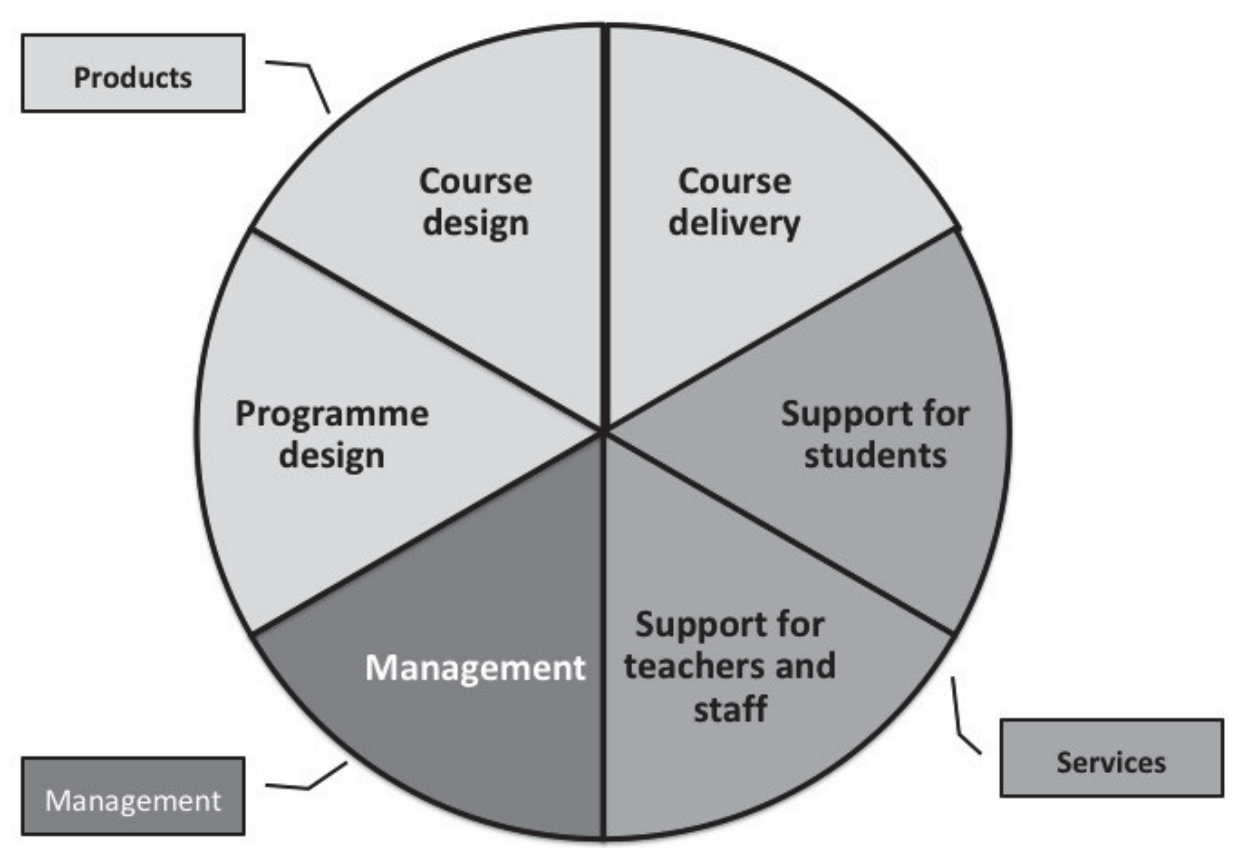

Figure 1: The three common quality areas and six quality dimensions in quality management models (Ossiannilsson and Landgren, 2012; Ossiannilsson et al., 2015).

Srikanthan and Dalrymple $(2002,2003)$ noted a mismatch between quality models for CQI and education. This mismatch consists of a focus on management and services at the expense of pedagogy (Srikanthan and Dalrymple, 2003, 2002). According to Abdous '[...] because of this perceived disconnection (Srikanthan and Dalrymple, 2003) CQI is considered more applicable to management and student services [...]' (Abdous, 2009) than it is to educational processes (the products in figure 1). Srikanthan and Dalrymple (2002) make the case that a model for effective CQI management in education must not only be systemic and address management and services but must also explicitly address the pedagogical aspects (Srikanthan and Dalrymple, 2002). Hansson et al. (2008) confirm this need for the context of OBL claiming that indeed all quality dimensions should be aligned in a functional manner focused on pedagogy: they must '[...] fit together in a coherent manner on the basis of a pedagogical philosophy' (Hansson, 2008, p.40). If educational processes are addressed, CQI principles can help institutions to implement, assess and improve OBL successfully (Moskal, Dziuban and Hartman, 2013; Srikanthan and Dalrymple, 2003). For instance if it appears that the pedagogical design (the courses and the programme) - which covers aspects of content, learning goals, methods and materials - is not in line with the students learning needs, the institution should take additional actions to address this (Ehlers, 2004). If this is so in the example we introduced in the section above, providing additional support for students to use technology might not suffice. This is likely insufficient since scholars in the context of OBL agree e.g. that OBL environments coerce students to take ownership of their learning process (Ehlers, 2004). It is therefore, likely that improvement measures need to focus on improving the pedagogical design in the dimensions of 'course design' or 'programme design' for students to take ownership. To inform such improvement measures, the pedagogical 
processes specific for $\mathrm{OBL}$, need to be explicitly present in the quality model that is used. While these pedagogical processes are not lacking from the traditional models for quality management (Hansson, 2008; Marshall, 2010; Williams et al., 2012), they are not explicitly present (Blieck et al., 2018). Since the last decade, several studies have empirically identified the needs of students related to OBL, including needs related to pedagogy (Ehlers, 2004; Jung, 2011, 2012; Ossiannilsson and Landgren, 2012). One of these studies, the conceptual quality framework for OBL proposed by Ossiannilsson and Landgren (2012). In the literature on quality management, the terms 'model' (e.g. Ossiannilsson et al., 2015) and 'framework' (e.g. Ossiannilsson and Landgren, 2012) are used interchangeably. In both cases it is a model or framework that is used for quality management. The conceptual quality framework for OBL proposed by Ossiannilsson and Landgren (2012) is unique because it introduces success factors for OBL that makes the pedagogical needs of students related to the quality areas: management, services and products explicit (figure 2). Three of these success factors are related to pedagogy (McLoughlin and Lee, 2008). Success in OBL is described as: '[...] to be successful in elearning from an academic and educational point of view but also with regard to their personal and social life' (Ossiannilsson and Landgren, 2012, p.49).

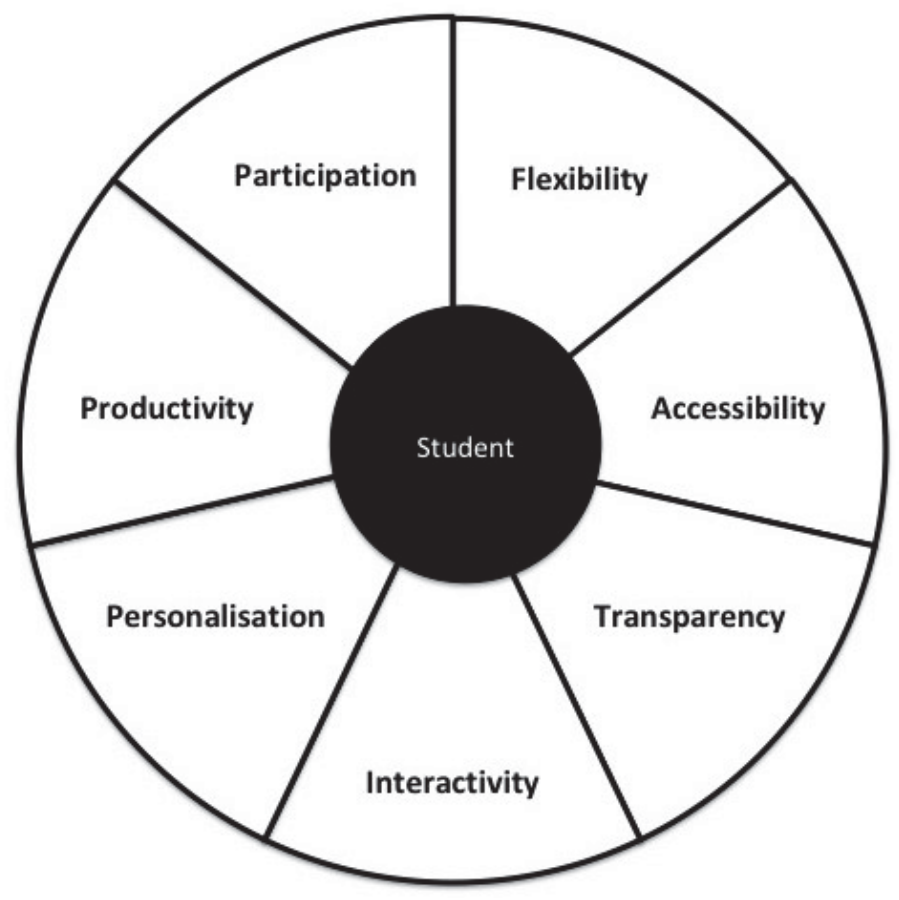

Figure 2: The needs of students related to OBL captured in success factors (Ossiannilsson and Landgren, 2012).

\section{Problem statement}

As no guidelines on how to use this conceptual quality framework are given, there is a need for scientifically validated knowledge on 'how' professionals can implement this conceptual quality framework, which explicitly address pedagogy, for effective quality management of OBL (Ehlers, 2007; Inglis, 2008). The objective of this contribution is therefore to answer the research question: 'how' can a conceptual quality framework that captures the needs of students (Ossiannilsson and Landgren, 2012) for effective CQI management of OBL be implemented? And, more specifically, to anwer this question against the context of AE in Flanders (Belgium).

\subsection{Context: the case of Flanders (Belgium)}

Adult education in Flanders (Belgium) is recognised, financed, and subsidised by the Flemish community. In Flanders (Belgium), Centers for Adult Education (CAE) cater to a wide range of target groups. To meet the needs of these adult students in terms of accessible and flexible education, the Flemish government, at the macro level, promotes OBL (Vlaams Parlement, 2007). As a result of the promotional policies of the Flemish government, OBL has been increasingly adopted in CAE. As demand increases, staff of CAE at both micro and meso levels, urgently need scientifically grounded quality instruments along with indicators and guidelines to manage the quality of OBL. However, quality models suited for $O B L$ in $A E$ are rare in the literature. Due to the lack of quality models for OBL in $A E, C A E$ have to use what is available in the context of HE for CQI of OBL. Regarding this CQI in CAE, the Flemish inspectorate reports, that at the management level (meso level) it is 
sufficient to strong in most CAE and that course teams (micro level) either strongly or sufficiently support the meso level. The majority of CAE have sufficient capacity to innovate which means that a culture focused on innovation and improvement was installed in the CAE (strategical adoption). However, CAE struggle with the use of data in quality management (quality assurance). While it is common practice in CAE to derive data from student and teacher surveys, at times these are insufficiently comprehensible to students (De Niel et al., 2016). Finally, CAE adopt an ad hoc approach to data analysis resulting in superficial analysis and ad-hoc quality improvement (De Niel et al., 2016) undermining the effectivity of CQI. To conclude, although large amounts of data are available, there is hardly any monitoring, not least because data registration is not coherent and a number of concepts are ambiguously defined (De Niel et al., 2016).

In Flanders, the field of AE can benefit from a comprehensive and contextualised quality model and instruments for $O B L$ that are in line with the principles of CQI, i.e., strategical adoption, quality assessment, and the improvement of OBL. Care should be taken to ensure that quality is captured in clear concepts, including those related to pedagogy, and that quality indicators allow effective CQI management of OBL from strategical adoption, over quality assurance towards continuous quality improvement. Second, adult education providers in CAE can benefit from an approach with scientifically sound guidelines for effective quality management. More specifically, guidelines on how to use data during CQI management in practice. Addressing these gaps in the field of $A E$, while taking the necessary improvements mentioned previously into account, makes this highly challenging and demanding contribution relevant beyond the context of $A E$.

Departing from the research context of AE in Flanders, we rephrase the general reseach question as 'how' can a conceptual quality framework that captures the needs of students (Ossiannilsson and Landgren, 2012) for effective CQI management of OBL be implemented in AE?, and, split it into three specific research questions:

1. 'how' can internal stakeholders in CQI of OBL implement a conceptual quality framework that captures the needs of students to strategically adopt OBL in AE? (srq1)

2. 'how' can internal stakeholders in CQI of OBL implement a conceptual quality framework that captures the needs of students for quality assurance of $\mathrm{OBL}$ in $\mathrm{AE}$ ? (srq2)

3. 'how' can internal stakeholders in CQI of OBL implement a conceptual quality framework that captures the needs of students be implemented for quality improvement of OBL in AE? (srq3)

\section{Methods}

To answer this research question a conceptual paper was chosen (Cropanzano, 2009). A conceptual paper is not based upon empirical data but summarises and integrates recent research, presents an integrated framework and highlights directions for future research (Gilson and Goldberg, 2015; Cropanzano, 2009). In conceptual contributions, the focus lies on developing logical and complete arguments for associations rather than testing them empirically. In line with the recommendations of Gilson and Goldberg (2015) we take a problem-focused approach i.e. effective CQI management in online and blended learning and link work across disciplines to broaden the scope on thinking about effective CQI management. Given that a review is not the sole focus of a conceptual paper, that section in this article is tightly focused on the literature within the domain of effective CQI management (Gilson and Goldberg, 2015). We focus on contributions that could explain and answer the challenges i.e. specific research questions with effective CQI management for the specific context of $A E$ in Flanders. In contrast to a systematic review of the literature, we selected a subset of studies that were chosen based on authors selection, to answer the "what's new" question that distinguishes a conceptual paper from a review, and on availability.

In the next section we conceptualise $\mathrm{OBL}$ and the challenges it presents for institutions that adopt it and the consequences it has for the internal stakeholders involved in the quality management. Then, we introduce the answer to the specific research questions describing how the conceptual quality framework by Ossiannilsson and Landgren (2012) can be implemented together with a scientifically valid approach for effective quality management of OBL. In the fifth section we provide the background and underpinning for the different elements in the conceptual model for effective quality management in relation to OBL. We explain how, according to the recommendations of Gilson and Goldberg (2015), the problem-focused approach in this paper allows to link and integrate work across research fields in order to answer the research question. In the final section we conclude with critical suggestions for future research based on the proposed conceptual model for effective quality management of OBL. 


\section{A conceptual model for effective quality management of $\mathrm{OBL}$}

\subsection{Online and blended learning and the internal stakeholders in CQI of OBL}

Different types of $O B L$ have emerged in education in the past two decades and are referred to in the literature as e.g. e-learning, blended learning or distance education (Boelens, De Wever and Voet, 2017). Most of these types are defined as a combination of online and face-to-face learning (Boelens, De Wever and Voet, 2017) and all can be situated in the continuum between face-to-face learning (no technology) and fully online learning (all technology) (OECD, 2005) with blended learning in between the endpoints. According to Boelens et al. (2017), blended learning remains an ill-defined concept which they describe at the course level as: "[...] learning that happens in an instructional context which is characterised by a deliberate combination of online and classroombased interventions to instigate and support learning" (p. 2). It is possible that courses are delivered completely face-to-face, blended or completely online as part of a programme that can be considered to be blended. We can thus extend the concept of Boelens et al. (2017) to the programme level. Institutions that adopt OBL need to address this new educational mode in the institutional quality management strategy (Hansson, 2008). Effective quality management of OBL starts with the strategical adoption (SA) of OBL and demands that quality assurance (QA) provides the information needed to initiate a phase of quality improvement (QI) (Abdous, 2009; Williams, 2016).

Because OBL reaches up, down and through the entire organization, a broad group of internal stakeholders at the meso (management) and micro level (faculty) is responsible for quality (Deepwell, 2007). This implies that a team must be assembled involving professionals from both levels of the organization in CQI. In accordance with the principles of CQI, a quality model and approach for effective management should be put into place to help professionals adopt, set goals, identify resources and strategies, and measure progress towards the institutions' vision (Moore, 2005; Moskal, Dziuban and Hartman, 2013).

We assume that the conceptual quality framework developed by Ossianilsson and Landgren (2012) is essential to strategically adopt OBL to meet students' needs in OBL programmes. If, at the level of success factors, quality instruments provide clear concepts, quality expectations between stakeholders and students can be clarified and assessed at the indicator level. First, this will enable the dialogue between internal stakeholders, at the meso and micro level, to set goals, identify resources and strategies, and measure progress towards the institution's mission and vision for OBL. While it is important that professionals involve students as part of CQI, the literature mentions several practical problems in the case of OBL (Jara and Mellar, 2009; Ehlers, 2007; Moskal, Dziuban and Hartman, 2013). Therefore, it can be useful to consult students to assess whether the quality of $\mathrm{OBL}$ is in line with their needs. Second, if the success factors are connected to the quality dimensions, quality instruments can help to consult students to detect and clarify opportunities for improvement in the institution.

\subsubsection{Development and validation of two quality instruments to involve the internal stakeholders in CQI for $O B L$}

Departing from the assumption that the conceptual quality framework by Ossianilsson and Landgren (2012) can provide a narrative for dialogue between professionals and consultation with the students, Blieck et al. (2017, 2018 and 2019) developed and validated two quality instruments in the context of adult education. The development and validation of the instruments was informed by the recommendations of Inglis (Inglis, 2008). First, since the quality framework (Ossiannilsson and Landgren, 2012) was derived from higher education, it is important to verify whether the concepts are relevant in adult education (Inglis, 2008). Next, quality indicators that have proven their value in HE must also be contextualised to adult education (Inglis, 2008). Finally, the structure of a quality framework must be tailored to the way it is meant to be used (Inglis, 2008). In this particular case, to support dialogue and consultation to strategically adopt, assess, and improve the quality of OBL.

To address these recommendations, two quality instruments were validated in line with the principles of designbased research (Amiel and Reeves, 2008; Barab and Squire, 2004; Herrington et al., 2007; Reeves, 2006). The result is the hybrid conceptual quality model depicted in figure 3 (Blieck et al., 2017). In this model, a limited number of quality indicators are linked to both success factors and to the established quality areas and quality dimensions in extant quality models e.g., 'the ratio between contact education vs. online education (flexibility) of the programme (design of the programme) matches the needs of the students. The success factors and quality indicators are important in enabling adult students to participate in OBL. Credibility, transparency, 
flexibility, and accessibility are assumed to facilitate student participation in $\mathrm{OBL}$ while interactivity, personalisation, and productivity relate to the pedagogy of OBL (Blieck et al., 2017, 2018).

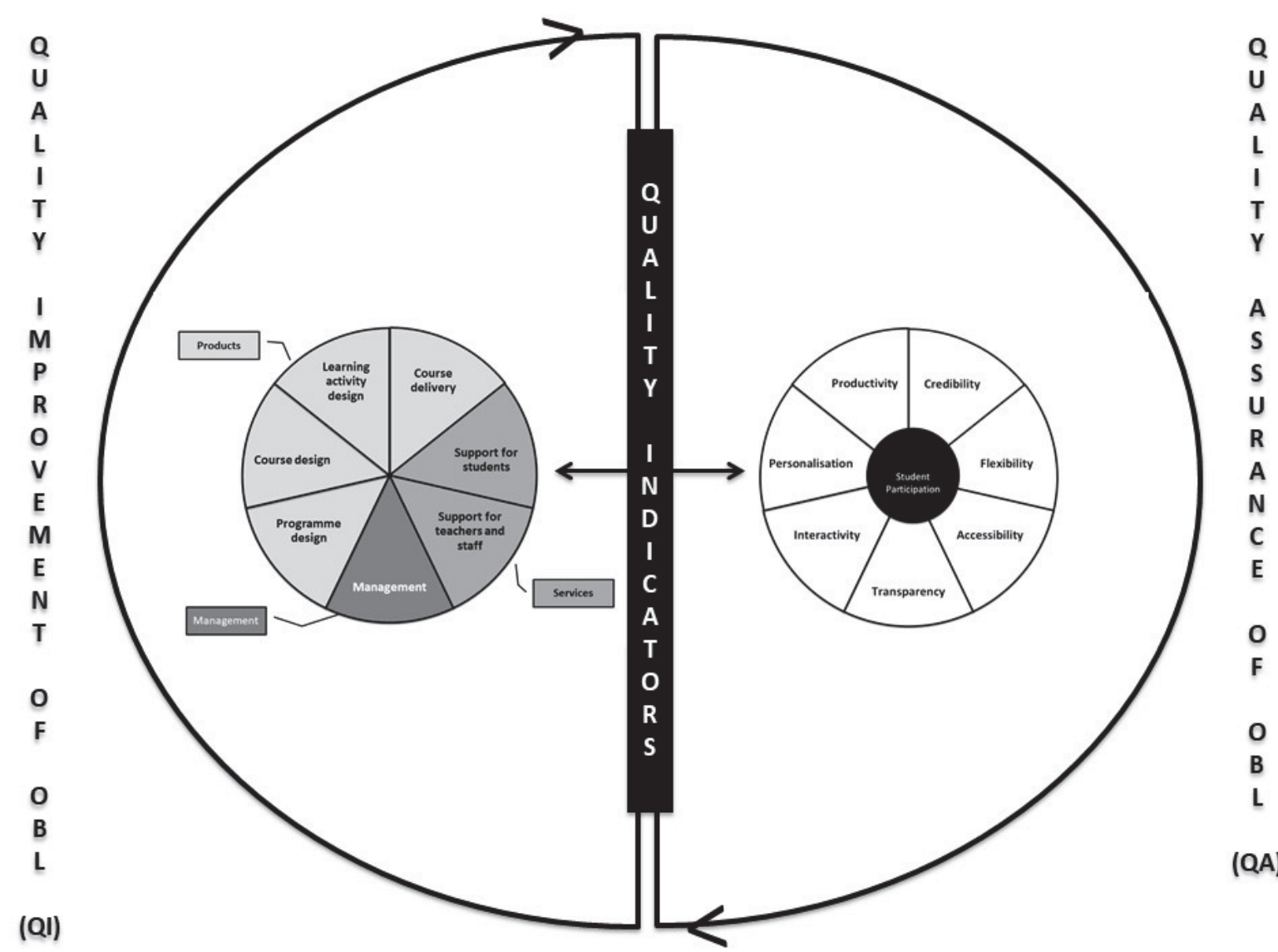

Figure 3: Hybrid conceptual quality model connecting success factors and quality dimensions with quality indicators (Blieck et al., 2017).

From this conceptual quality model, Blieck et al. (2017) derived and validated two instruments for effective CQI management of OBL. The first of these (Blieck et al., 2018) presents a list of quality indicators and comprehensively described success factors that underpin the SA of OBL (qiSA-OBL) and aligns all quality dimensions within institutions in accordance with this vision (Hansson, 2008; Kipta and Berge, 2006). Because all success factors depend upon the adoption of $\mathrm{OBL}$, priorities can be set at the level of the indicators (Blieck et al., 2018).

The second instrument (Blieck et al., 2019) is relevant for the quality assurance of $\mathrm{OBL}$ and to guide internal quality improvement of OBL (qIQA\&I-OBL). Usually, student satisfaction is chosen as an indicator for effective CQI in education (Ardi, Hidayatno and Zagloel, 2012). However, taking the reported drop-out rates of students in OBL into account (Nistor and Neubauer, 2010; Rovai, 2003) along with how Ossiannilson and Landgren (2012) describe success in OBL, sustained and successful student participation (Nistor and Neubauer, 2010; Rovai, 2003) as chosen as a relevant indicator for effective CQI management of OBL (Blieck et al., 2018). In this survey students are consulted about the extent to which the success factors allowed them to participate in the OBL programme, the result informs the quality improvement.

We now conceptualise the implementation of these validated quality instruments for effective CQI management of OBL (Blieck et al., 2017, 2018, 2019); see also figure 4.

\subsection{A conceptual model for effective quality management of OBL}

In the case of OBL literature indicates that teams composed of management and faculty should participate in frequent meetings to develop (Nihuka and Voogt, 2011) and effectively manage the quality of OBL (Deepwell, 2007; Ehlers, 2007; Jara and Mellar, 2009). Dialogue between professionals at various levels of an educational institution and consultation with the students is required to strategically adopt, assess and improve OBL 
successfully (Deepwell, 2007; Ehlers, 2007; Moskal, Dziuban and Hartman, 2013). To strategically adopt OBL several questions like e.g. 'Why should the institution engage in OBL?, what are the goals, and what outcomes are expected to be achieved, both initially and in the longer term?, what student benefits are sought -improved success, increased persistence, shortened time-to-degree, etc.?, demand an answer (Moskal, Dziuban and Hartman, 2013, p.16).

The strategical adoption of OBL (srq1): We assume that management and faculty, can use the success factors and the indicators mentioned in the qiSA-OBL (Blieck et al., 2017), which was derived from the work by Ossiannilsson and Landgren (2012). First, to engage in this dialogue to strategically adopt OBL in line with the institutions' vision during the planning-phase. Second, in line with this reason for adoption, to develop an OBL programme and courses tailored to the needs of adult students, both pedagogical and other, to participate in the educational offering. We assume that the adoption and development of the management and faculty will elicit concerns.

The concerns of the team members are important to prepare to access and collect data to explore a problem or investigate hypotheses (plan-purpose). We identify data in line with Lai and Schildkamp (2013, p. 10) as the '[...] information that is collected in a systematic manner and organised to represent some aspect of schools [...]', or an educational institution. In the case of OBL the reported attrition rates indicate that student participation can be an issue (Nistor and Neubauer, 2010), therefore we suggest that student participation in OBL is taken as an indicator for effective CQI as alternative for, or in addition to, other indicators such as student satisfaction (Ardi, Hidayatno and Zagloel, 2012). The success factors in the qiSA-OBL (Blieck et al., 2017) are important in formulating research questions or hypotheses when preparing to investigate and purposefully (purpose) monitor student participation in $\mathrm{OBL}$, or what can influence student participation, alongside other outcomes such as student satisfaction.

The quality assurance of OBL (srq2): During implementation of the OBL courses and programme, the team accesses and collects data to purposefully monitor student participation or what can influence participation in $\mathrm{OBL}$, next to other outcomes like e.g. student satisfaction. This is important to ensure purposeful quality assurance (do-data). At the end of the implementation phase the effect of the CQI management must be assessed (check-information). Because student input is valuable in guiding the improvement process (Harvey, 2003), stakeholders can consult with students to check and assess if the quality of the OBL programme and courses meets their needs, and get feedback e.g. by survey data at the end of the implementation phase. The qiQA\&I-OBL (Blieck et al., 2019) can be used for this purpose. Students are consulted to check and assess the (perceived) effectivity of OBL programmes in a reliable and valid manner, for instance in terms of whether the quality of the $\mathrm{OBL}$ programme and courses meets their needs. In this survey, students report the extent to which the indicators and success factors enable them to participate in OBL. Team members combine this data in the check-phase with the, both qualitative and quantitative, data that they collected to monitor OBL during the implementation. Team members then filter, check, organise and analyse the data of OBL to explore a problem or investigate hypotheses (check-information). This provides information to the team members about the extent to which students were able to participate in $\mathrm{OBL}$ and it installs a feedback loop to initiate the quality improvement phase. In the case of adoption of $O B L$, this would be the first CQI-cycle resulting in a current state analysis in the check phase by the end of QA. The effects of improvement measures will need to be based on this information.

The quality improvement of OBL (srq3): During the reflect-phase the team members need to combine their understanding and expertise to install improvement measures in the institution. This is needed to convert the information into actionable knowledge to take informed decisions about what improvements i.e. management processes, services or pedagogical aspects of the products delivered to students (reflect-knowledge). The connections between the success factors and the quality indicators in the qiQA\&I-OBL (Blieck et al., 2019) are useful for this purpose (figure 4). 


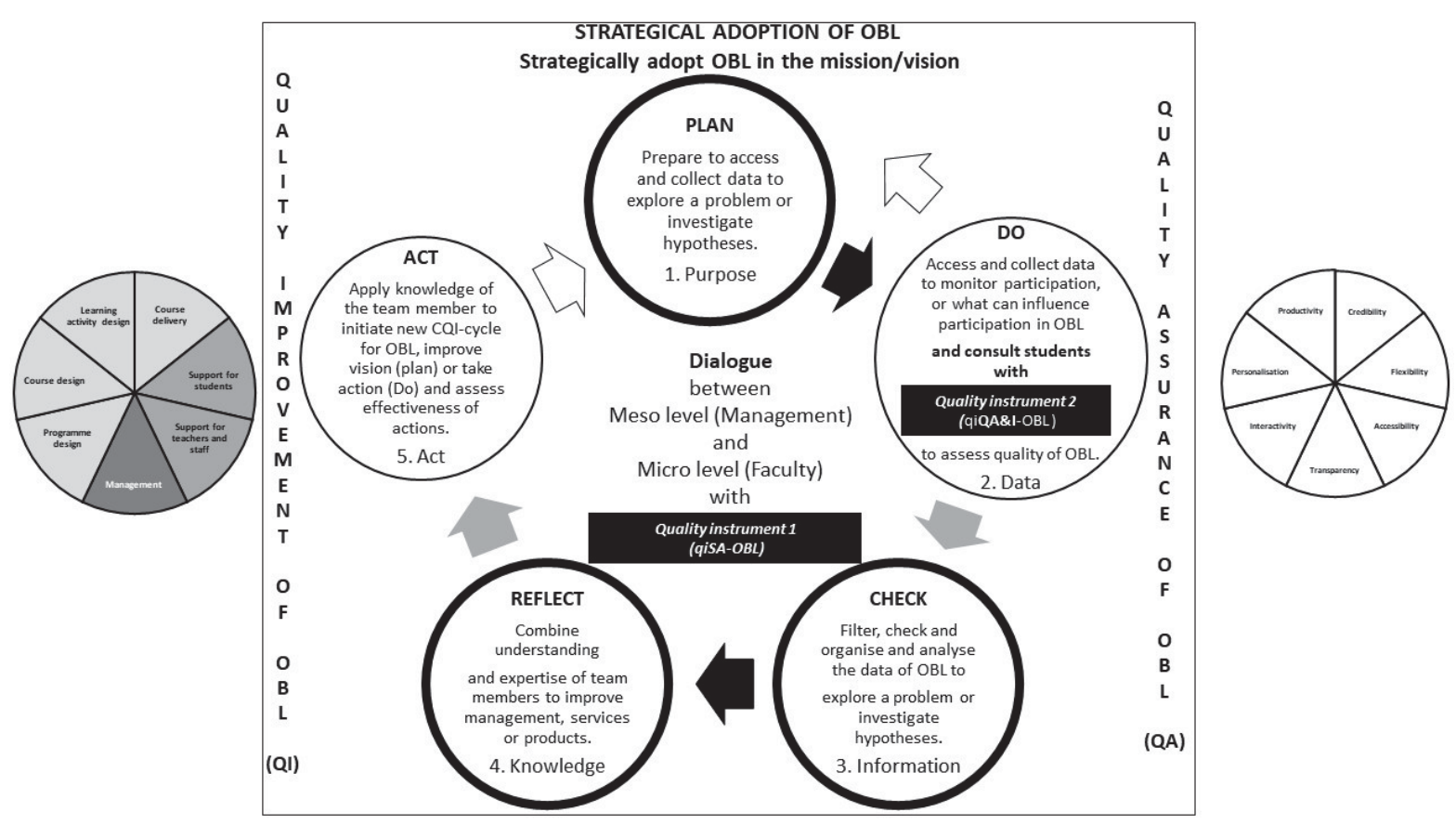

Figure 4: Conceptual model for effective quality management of OBL (based on Abdous, 2009; Berge, 1995; Deepwell, 2007; Ehlers, 2007; Jara and Mellar, 2009; Leiber, Stensaker and Harvey, 2015; Moskal, Dziuban and Hartman, 2013; Nihuka and Voogt, 2011; Schildkamp, Poortman and Handelzalts, 2015; Schildkamp et al., 2014, 2016; Sonpal-Valias, 2009; Harvey, 2003).

Finally, in the act-phase the knowledge of the team members is applied. There are two possibilities. Either the vision on $\mathrm{OBL}$ needs refinement, or improvements to management processes, services or the pedagogical aspects (the products) are needed. In both situations a new CQI cycle is initiated (plan). Several CQI-cycles are needed to assess mid-term and long-term effects of the quality management approach on student participation in OBL (Jara and Mellar, 2010, 2009).

The conceptual model for effective quality management supports to investigate the effectiveness of the quality management approach for OBL. In line with widespread use in literature we distinguish short-term, mid-term and long-term effects and refer to these respectively as outputs, outcomes and impacts (Leiber, Stensaker and Harvey, 2015). Leiber et al. (2015) reported that the terms 'effect' and 'impact' e.g. 'impact evaluation' or 'impact analysis' are both used as umbrella terms. Like Leiber et al. (2015), we choose to use 'effect' as an umbrella term.

This conceptual model for effective quality management of OBL is relevant for several reasons. First, it presents a scientifically valid quality management approach to foster dialogue between all stakeholders in an institution and consultation of students. Second, combined with the quality instruments (Blieck et al., 2017, 2018, 2019) derived from the framework by Ossiannilsson and Landgren (2012), it can support institutions to implement a CQI management approach to adopt, develop, monitor, assess and improve OBL to meet the (pedagogical) needs of students.

\section{Background for the conceptual model for effective quality management of $O B L$}

In this section, we first address literature on effective CQI management of OBL. We introduce the general principles, a quality indicator and a common problem in effective CQI management for OBL. Then we present research that clarifies the causes of this common problem of CQI management in the context of OBL. Since this research points to the use of student (feedback) data to address this common problem we link the field of databased decision making (DBDM) to the field of CQI. We explain how DBDM is a driver for effective CQI management of OBL.

\subsection{Effective CQI management of OBL}

Since Deming (1950), CQI management is identified as different variants of the plan, do, check, reflect and act cycle (Moen and Norman, 2010). We identify CQI in accordance with Sonpal-Valias (2009) as: plan-do-check- 
reflect and act (figure 5). Effective CQI implies that quality assurance (QA) and quality improvement (QI) follow and inform each other as part of a continuous cycle (Williams, 2016). In practice, this means that first a QAphase is initiated in which: OBL programmes and services are strategically planned and developed (plan), implemented (do); and that quality is monitored during and assessed by the end of the implementation (check). This QA-phase provides feedback for the QI-phase. This phase starts when the results from the QA-phase are checked (check) and interpreted (reflect) and decisions to improve are taken (act). Thus initiating a subsequent CQI-cycle.

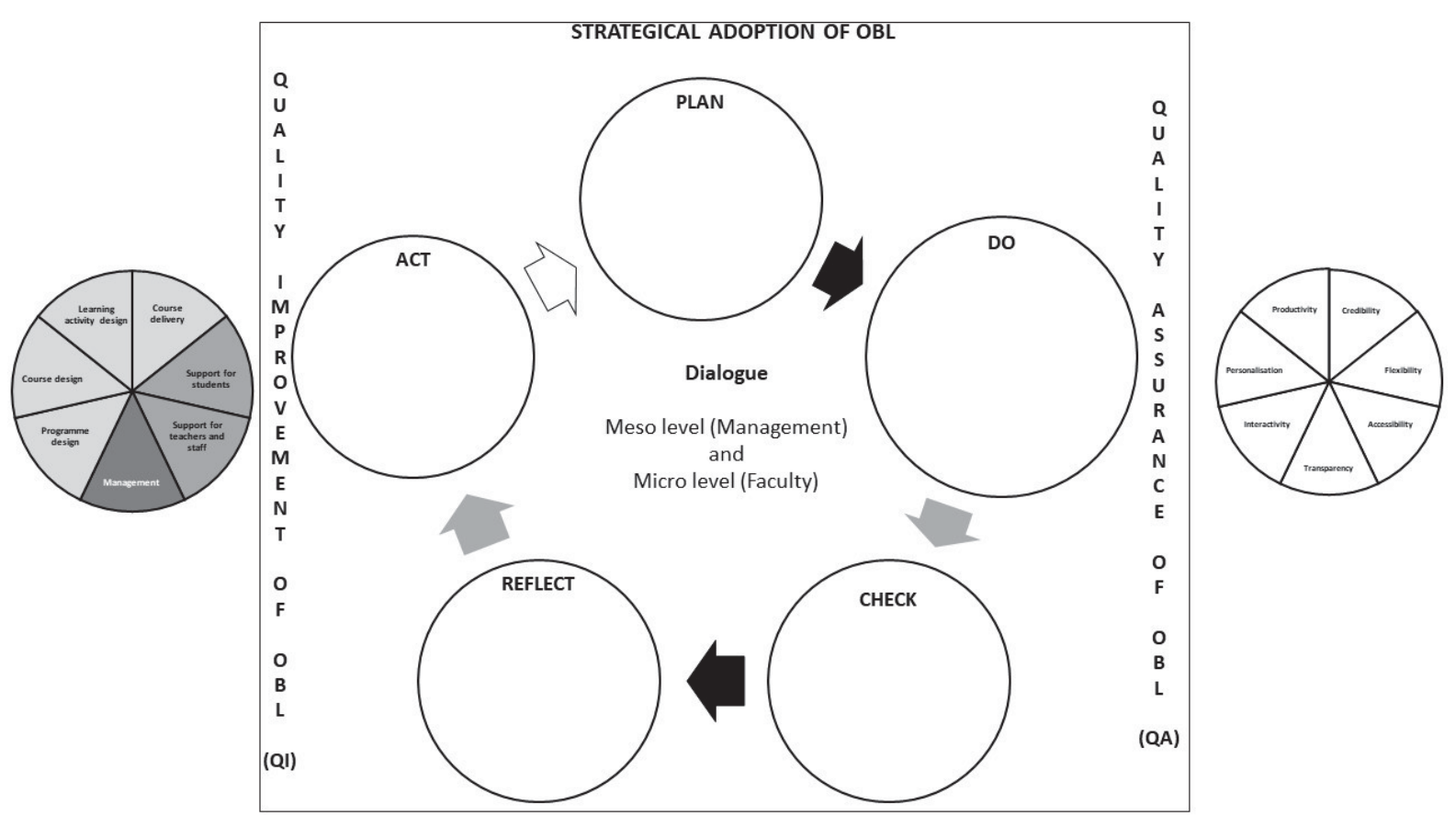

Figure 5: The conceptual quality model of Ossiannilsson and Landgren (2012) can support effective CQI

\subsubsection{Student participation as an indicator for effective CQI management of OBL}

We argued that sustained and successful student participation is a relevant indicator for effective CQI of OBL as alternative for, or in addition to, other indicators such as student satisfaction (Ardi, Hidayatno and Zagloel, 2012).

Nistor and Neubauer (2010) describe sustained and successful student participation in OBL as: "[...] learners completing the activities specified in the seminars' didactical concept" (p. 664). Two dimensions of participation in $\mathrm{OBL}$ are distinguished. First, students can choose to participate actively in the interaction with peers and teachers about the (online) learning content, which is coined as: 'active participation' (Nistor and Neubauer, 2010, p.664). Students can also choose to 'lurk' i.e. 'only consume without producing information', which is referred to as 'passive participation' (Nistor and Neubauer, 2010, p.664). In the latter case, students make, at best, passive use e.g. read the online content and digital traces of the online interaction to complete learning activities. Effective CQI of OBL will ultimately lead to improved student participation in OBL.

\subsubsection{A common problem in effective CQI management of OBL}

While scholars take different perspectives on the relationship between QA and QI, some acknowledge that: '[...] they are part of a cycle, each part informing the next' (Williams, 2016, p.101). Such a feedback loop is crucial for quality improvement (Bloxham, 2010; Harvey, 2003). Effective CQI management needs a simultaneous focus on QA and QI (Abdous, 2009). Yet scholars report that institutional CQI of OBL usually focuses on QA at the expense of QI (Jara and Mellar, 2009; Abdous, 2009; Williams, 2016). In the case of OBL, Abdous (2009, p. 382) showed that CQI '[...] can be transformed from a static, after-the-fact state to a more iterative and dynamic state [...]', if QA is intertwined with the development (Plan) and implementation process (Do) of OBL. While the conceptual framework for quality of OBL (Ossiannilsson and Landgren, 2012) is useful for effective CQI, the research question is, 'how' the implementation of this conceptual quality framework that captures the needs of students for effective CQI management of OBL can be implemented for effective CQI management?

\subsection{Linking the field of Data-Based Decision making to the field of Continuous Quality Improvement}


Deepwell (2007) emphasises that a broad group of professionals at all levels of an institution is responsible for the quality of $O B L$ (figure 4). A distinctive feature of $O B L$ is e.g. its dependence on institutional infrastructure and access to technologies beyond the control of the faculty (Deepwell, 2007). The implication is that management and faculty, both stakeholders in CQI for OBL need to engage in a dialogue. CQI management for $\mathrm{OBL}$ is therefore to be implemented at the intersection of the meso (management) and micro (faculty) level of an institution (Deepwell, 2007; Ehlers, 2007). However, CQI management requires the participation of 'all' stakeholders, including the consultation of students (Deepwell, 2007; Ehlers, 2007). The research question is therefore restated to 'how' can the conceptual quality framework that captures the needs of students be implemented to foster dialogue and consultation between the stakeholders to achieve effective CQI management of OBL? We address this question in the section below and offer an answer. To come to this, we discuss studies that highlight challenges to achieve coherence in CQI management of OBL. We present a scientifically state of the art approach for effective quality management that supports dialogue between professionals, during the entire CQI-cycle, and consultation of students.

\subsubsection{Data-Based Decision Making as a driver for effective CQI management of OBL}

In their case study, Jara and Mellar (2009) reported four main factors related to the features of OBL that disrupt the effectiveness of CQI management for OBL. Three of these factors challenge the installation of a dialogue between management and faculty in CQI (Jara and Mellar, 2009). The fourth factor presents challenges to consult students during CQI of OBL.

First, in relation to management and faculty, developing an OBL programme and courses is complex and demands different skills, leading to disaggregated processes. Second, this demands that different professionals in different roles are involved in the development and implementation of OBL courses, which lead to a distributed configuration of these teams. Third, as a result of the organizational position that courses have within institutions not all professionals are equally available. These three factors indicate that institutions need to adapt their CQI management approach to be suited for OBL (Jara and Mellar, 2009). Jara and Mellars' (2009) study suggests that CQI management of OBL, addressed from a team perspective, can be beneficial. It is interesting to note that current literature on the development of OBL programmes and courses embraces a collaborative approach such as in multidisciplinary teams or teacher design teams (Nihuka and Voogt, 2011). This approach provides an answer, among other things, to the different roles and responsibilities a department faces when they develop and implement OBL (Berge, 1995). As part of their responsibility to develop and implement $\mathrm{OBL}$, faculty can participate in CQI of OBL together with management.

The fourth disrupting factor for CQI of OBL is that it is not straightforward to consult students (Jara and Mellar, 2009). The limited opportunities to interact with students puts pressure on the need to consult them in CQI of OBL (Jara and Mellar, 2009). To solve this issue, Jara and Mellar (2009) suggested that the faculty together with the management collect, analyse and act upon student (feedback) data from a wide range of instruments (e.g. interaction logs, observation, student surveys and student-tutor relationships) to effectively manage the quality of OBL.

It seems that data are drivers for quality improvement (Harvey, 2003; Inglis, 2008; Williams; 2016). In line with Inglis (2008) we assume that data, especially student feedback (Harvey, 2003), can be the driver for CQI. DBDM allows management and faculty to offset the fourth of the disrupting factors for CQI i.e. the difficulty to consult students (Jara and Mellar, 2010). Several studies about CQI for OBL confirm this statement. Bloxham (2010) used (formative) student feedback to monitor, assess and improve the development of online courses. Barrie et al. (2005) showed that a CQI management approach that uses data that was focused on student learning promoted coherence between quality assurance and quality improvement. A focus on DBDM in CQI can thus promote coherence between quality assurance and quality improvement. The DBDM-process is an inherent part of CQI since it was introduced by Deming (1950). Yet research indicates that DBDM is difficult to put into practice due to the features of OBL (Jara and Mellar, 2009). Next, as Schildkamp et al. emphasise that '[...] management and faculty often still do not use data to their best effect, if at all '[...]', and '[...] that decisions are still mainly based on intuition and limited observations [...]' (Schildkamp, Poortman and Handelzalts, 2015). It is therefore useful to make data use throughout the CQI-cycle explicit. This is helpful to support developing practitioners' competence in the use of data (Schildkamp and Kuiper, 2010) in quality management for OBL (Ehlers, 2007). Therefore, in the next paragraph we make DBDM in the CQI-cycle explicit. 
Data-based decision making (DBDM) as part of CQI. DBDM is '[...] an iterative and cyclic procedure [...]' (Schildkamp, Poortman and Handelzalts, 2015) that can be used by teams composed of management and faculty to use data collaboratively in a reflective dialogue within a school, using a structured approach [...]' (Schildkamp, Poortman and Handelzalts, 2015). Management and faculty operating as a team at the programme level offers an answer to the first three disrupting factors for CQI (Jara and Mellar, 2009). In such a constellation the expertise and efforts of these professionals, with their different roles, who are responsible for OBL in the institutions can be directed in a targeted manner both for developing (Nihuka and Voogt, 2011) and managing the quality of OBL. Schildkamp et al. (2015) identified DBDM as a cyclic procedure that can be used by teams:

'Data use in data teams starts with a purpose in the form of a problem definition and a related goal instead of with data. Next, data are collected to investigate possible causes of the problem. The team needs to filter the data (e.g. are the data valid and reliable? If not, additional data need to be collected and a feedback loop is created), organise the data to investigate the hypothesis, and analyse and interpret the data. Only then, these data are transferred into information. Combined with stakeholder understanding and expertise, this becomes actionable knowledge. Data teams can take two possible actions: The hypothesis is incorrect and the action is to go back to formulating new hypotheses (a feedback loop is created), or the hypothesis is correct and the data team takes action based on the data. In case of the latter, they also need to evaluate (collect new data) whether their actions have led to the desired outcomes and goal; in this way, another feedback loop is created.' (Schildkamp, Poortman and Handelzalts, 2015, p.4).

This typical DBDM-cycle (Schildkamp, Poortman and Handelzalts, 2015) can be integrated in the CQI-cycle, figure 6. When the DBDM-cycle is embedded in the CQI-cycle it can be used for two purposes i.e. process evaluation and effect evaluation (Schildkamp et al., 2014). In the case of process evaluation, an implementation process is monitored (Schildkamp et al., 2014). This is useful to explore (monitor) and assess the effects of what is implemented $(Q A)$. If a team adopts an innovation like $O B L$, only the implementation process of $O B L$ can be monitored and assessed (process evaluation). This first CQI-cycle results then in a current state analysis in the check phase (QA). Effect evaluation is only possible in a subsequent CQI-cycle. Effect evaluation is about whether improvement measures (QI) solve a problem (Schildkamp et al., 2014). This means whether the causes of a problem have been removed or that a problem has been solved and the goal has been achieved.

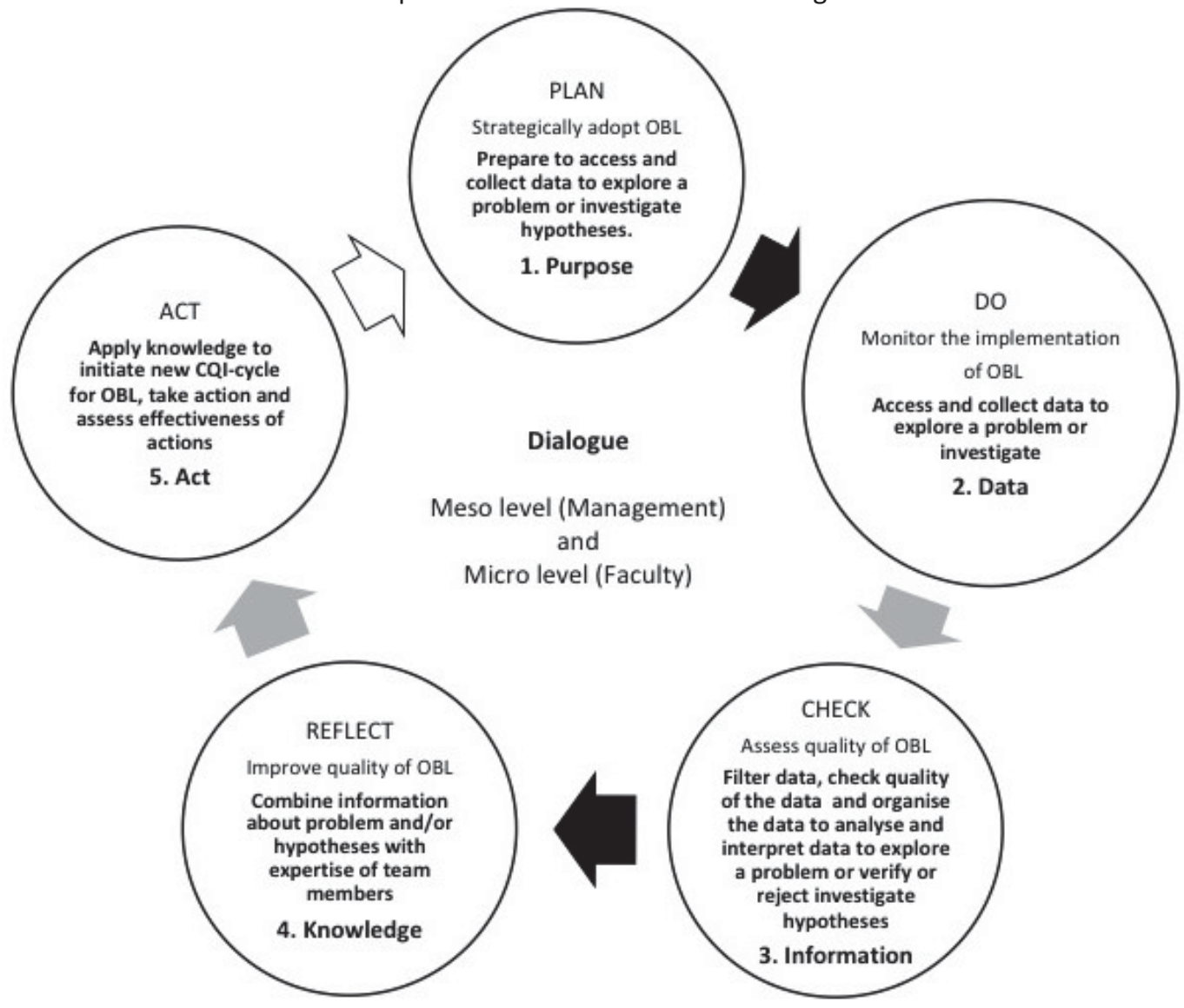


Figure 6: An integrated approach for effective CQI management of OBL: DBDM-cycle and steps integrated into the PDCRA-cycle.

The conceptual quality management model in this contribution is in line with literature in the fields of internal quality improvement and external quality assessment that emphasise the importance to systematically collect and analyse multiple data as a point of departure as a basis for decisions (Creemers and Kyriakides, 2010; Mutch, 2012; Vanlommel, Vanhoof and Petegem, 2016).

\section{Discussion}

The CQI management approach presented in this contribution is designed to be implemented with the conceptual quality framework for OBL by Ossiannilsson and Landgren (2012) and strategically adopt, monitor, assess and improve the quality of $\mathrm{OBL}$ in line with the needs of the adult students. We assume that the conceptual model for effective CQI management of OBL presented in this contribution can be used to investigate the effectivity of the CQI management approach. For these purposes Blieck et al. $(2017,2018,2019)$ developed and validated two quality instruments.

Assuming that the conceptualised model for effective CQI management of OBL described in this contribution provides an approach to implement the work of Blieck et al. $(2017,2018,2019)$ is one thing, achieving it quite another. To achieve this implementation, various concerns that the literature points to, need to be considered such as the relation to the external quality assurance (Mutch, 2012) and factors related to the quality instruments (Faddar et al., 2017) and the context (Schildkamp et al., 2016; Van Kemenade, 2017). Because it is not possible to address all concerns in this contribution, we address the two most important aspects in relation to the educational context in which our work is meant to be implemented i.e. adult education. The first is, when carried out in OBL settings, whether the use of the quality instruments in the CQI management approach presented in this contribution can influence the learning or educational process already in place. More specifically, transform the implemented pedagogy of the face-to-face programme to realise the full potential of a (re)designed OBL programme (Graham and Robison, 2007). The second, is the need to take contextual factors (e.g. characteristics of the organisation, the team, the professionals and the data) into account during the implementation of the CQI management approach (Schildkamp, Poortman and Handelzalts, 2015; Schildkamp et al., 2016).

\subsection{Critical reflections related to the implementation of the $O B L$ quality instruments}

While the quality instruments were validated for the context of adult education, have an explicit focus on OBL pedagogy and were designed to strategically adopt, develop, implement and assess OBL programmes (Blieck et al., 2017, 2018, 2019); they were used in an implementation study by Blieck (2018) in two contexts as part of their doctoral study. In this descriptive case study the researcher supported two teams consisting of management and faculty in different CAE, indicates that the quality instruments indeed support a quality dialogue between professionals (Deepwell, 2007; Ehlers, 2004, 2004; Ossiannilsson and Landgren, 2012) upon the adoption of OBL to take informed decisions to design and implement (QA) programmes for OBL (Blieck, 2018). However, the implementation was time intensive, spanning a period of 18 months, and resource intensive. With respect to this design of OBL programmes in education, it is important to take note that several stakeholders influence OBL design decisions i.e. management, faculty and learners (Shea, 2007). Therefore, it is crucial that the CQI approach supports management and faculty to implement OBL programmes that go further than increasing the convenience and productivity to learners (Graham and Robison, 2007). This means, firstly, to devote sufficient resources and time (management) to support and encourage the faculty to design OBL programmes focused on the pedagogical requirements of $\mathrm{OBL}$ programmes for adult learners. The time intensive implementation study by Blieck (2018) confirms these assertions. Secondly, in relation to this pedagogical design, it is important to take note of two observations. Firstly that several generations of distance education pedagogy emerged over time: cognitive-behaviourist, social constructivist and connectivist pedagogy (Anderson and Dron, 2011). The implemtation study by Blieck (2018) indicates that the quality instruments (Blieck et al., $2017,2018,2019$ ) allow to guide the decision process of practitioners towards the pedagogical elements of OBL. However, it remains unclear that the instruments are sufficiently generic to be compliant with these different pedagogical perspectives. This compliance is important for at least two reasons. Firstly, because in practice OBL programmes are seldom designed in accordance from one single pedagogical perspective (Anderson and Dron, 2011). Secondly, compliance is also important because all pedagogical perspectives add to the quality of the educational offering (Anderson and Dron, 2011). In sum, it remains thus to be seen if the instruments allow practitioners to re-design the learning or educational process that is already in place towards OBL programmes. 
Also, when quality assessment uncovers problems, to what extent the quality instruments allow professionals to evolve towards an optimal educational design in terms of OBL pedagogy that is aligned with the needs of the adult students and balanced with the management infrastructure and resources. Because the implementation study by Blieck (2018) ended upon completion of the quality assurance phase, it did not allow to investigate the effictivity of the CQI management approach on the educational design.

\subsection{Critical reflections related to the effective quality management approach for $\mathrm{OBL}$}

Both CQI and DBDM happen in a context that is influenced by characteristics of the organization, the team and its members (Abdous, 2009; Bloxham, 2010; Jara and Mellar, 2009, 2010; Schildkamp, Poortman and Handelzalts, 2015; Schildkamp et al., 2016). These (perceived) characteristics can act as catalysts or hinder implementation of effective CQI of OBL. With respect to the conceptualised approach for effective CQI management of $\mathrm{OBL}$ in this paper, it should be noted that it is generic and the design of the approach has been derived from literature in the context of higher education. Since scholars such as Van Kemenade (2017) contend that contextual elements affect $\mathrm{CQI}$ at the interface between the meso and micro level, it is not clear if and to what extent it can be implemented in different educational contexts. Because the implementation study by Blieck et al. (2018) was conducted in only two cases this question remains largely unanswered. Van Kemenades' (2017) main argument is that, like quality models and their instruments, generic principles of quality management need to be adapted to different educational contexts. This is in line with the ICDE's (Ossiannilsson et al., 2015) recommendation to assist institutions in adapting a (generic) quality management approach to their specific context, i.e., adult education. This is important because, there are practical issues involved in implementing quality models for effective CQI of OBL in HE (Jara and Mellar, 2009).

It is thus important to expand scientific knowledge on the context elements that are at play during the implementation (Abdous, 2009; Bloxham, 2010; Jara and Mellar, 2009, 2010; Schildkamp, Poortman and Handelzalts, 2015; Schildkamp et al., 2016). It remains to be seen whether the approach for effective CQI management can offset two important challenges related to the features of OBL (Jara and Mellar, 2009). First, if acting as a team can offset the features of OBL that challenge the involvement of the stakeholders at the interface between the meso level and micro level, and the consultation with students (Jara and Mellar, 2009). Second, if the explicitation of the DBDM-approach in CQI management alone will allow practitioners to achieve coherence between quality assurance and quality improvement (Abdous, 2009; Jara and Mellar, 2009). Taking research such as Schildkamp, Poortman and Handelzalts (2015) and Schildkamp et al., (2016) into consideration it is likely that teams comprised of management and faculty will need support in DBDM. This will be crucial to offset the factors at the level of the organization, the team (members) and the data (Schildkamp et al., 2016).

It is thus important in implementation studies (Blieck, 2018) to take the context in which quality models and instruments are implemented into account. This is important to assess transferability to other contexts. Despite the efforts of the researcher (Blieck, 2018) to provide an indication for the transferability of the findings in the implementation study by means of a thourough context description the number of cases to draw conclusions from remained limited. Therefore, we agree with the recommendation to explore suitable participation methods to involve all stakeholders, i.e., providers and students, through dialogue to achieve effective institutional quality management of OBL in education (Ehlers, 2004; Ossiannilsson and Landgren, 2012) and AE in particular (Ossiannilsson et al., 2015; Van Kemenade, 2017).

\subsection{Suggestions for further research}

We advise exploratory case study research (Yin, 2009) with the conceptual framework (Ossiannilsson and Landgren, 2012). This will inform practitioners how the different education providers (teachers and trainers (in all their roles), course designers and management) can engage and use the quality framework by Ossiannilsson and Landgren (2012). These studies are important to confirm the generic implementation principles of the approach for effective CQI management of OBL in different educational contexts (Van Kemenade, 2017) and enable mid-term and long-term effectivity research. Next, we advise that case studies in the field also investigate the contextual elements (Yin, 2009). Although elements such as institutional context, team, data, and selfcharacteristics lay beyond the scope of this contribution we advise to examine how these elements can interfere with or strengthen the quality management approach (Abdous, 2009; Bloxham, 2010; Deepwell, 2007; Jara and Mellar, 2009, 2010; Schildkamp, Poortman and Handelzalts, 2015; Schildkamp et al., 2016; Van Kemenade, 2017). Expanding the implementation research to a sufficient number and diversity of institutions is necessary to establish generic principles for implementation, for instance by uncovering the contextual factors that are at play. Investation of these contextual factors is important to gain insight into the transferability of the findings to 
other contexts. A final route for future research is to implement the quality instruments by Blieck et al. (2017, $2018,2019)$ together with traditional quality models for OBL (Hansson, 2008; Marshall, 2010; Williams et al., 2012), or even generic quality models in education, as the hybrid structure of these quality instruments would allow this.

\section{Conclusion}

In this conceptual paper we presented an approach for effective CQI management of OBL at the intersection of the meso and micro level. The approach integrates key findings from the fields of CQI (of OBL) and DBDM.

Effective CQI management (of $\mathrm{OBL}$ ) needs coherence between quality assurance and quality improvement. Such coherence can be reached when management and faculty operate as a team, through dialogue, and consult the students, following a data driven approach. Multiple data sources are systematically collected to monitor and assess the implementation process and complemented with student feedback data to decide how to improve the quality of OBL and later assess the effects (Creemers and Kyriakides, 2010; Mutch, 2012; Vanlommel, Vanhoof and Petegem, 2016). Student participation in OBL is assumed as a suitable indicator for effective CQI next to, or in addition to, other quality measures (Ardi, Hidayatno and Zagloel, 2012).

\section{Acknowledgement}

We would like to acknowledge the project 'Adult Learners Online!' financed by the 'AGENTSCHAP INNOVEREN \& ONDERNEMEN' of the Flemish government (Project Number: IWT140029), which made this research possible.

\section{References}

Abdous, M., 2009. E-learning quality assurance: a process-oriented lifecycle model. Quality Assurance in Education, 17(3), pp.281-295.

Amiel, T. and Reeves, T.C., 2008. Design-based research and educational technology: Rethinking technology and the research agenda. Educational Technology \& Society, 11(4), pp.29-40.

Anderson, T. and Dron, J., 2011. Three generations of distance education pedagogy. The International Review of Research in Open and Distributed Learning, 12(3), pp.80-97.

Ardi, R., Hidayatno, A. and Zagloel, T.Y.M., 2012. Investigating Relationships among Quality Dimensions in Higher Education. Quality Assurance in Education, 20(4), pp.408-428.

Barab, S. and Squire, K., 2004. Design-Based Research: Putting a Stake in the Ground. Journal of the Learning Sciences, 13(1), pp.1-14.

Barrie, S., Ginns, P. and Prosser, M., 2005. Early impact and outcomes of an institutionally aligned, student focused learning perspective on teaching quality assurance. Assessment \& Evaluation in Higher Education, 30(6), pp.641-656.

Becket, N. and Brookes, M., 2005. Analysing quality audits in higher education. Brookes ejournal of learning and teaching, 1(2), pp.1-12.

Berge, Z.L., 1995. The role of the online instructor/facilitator. Educational technology, 35(1), pp.22-30.

Blieck, Y. 2018. Development and Validation of A Conceptual Quality Management Model for Effective Institutional Continuous Quality Improvement of Online and Blended Learning in Adult Education, PhD thesis, Vrije Universiteit Brussel, Brussel, 7 November, available at: 10.13140/RG.2.2.16959.15523.

Blieck, Y., Kauwenberghs, K., Zhu, C., Struyven, K., Pynoo, B., Depryck, K., 2019. Investigating the Relationship between Success Factors and Student Participation in Online and Blended Learning in Adult Education. Journal of Computer Assisted Learning. https://doi.org/10.1111/jcal.12351

Blieck, Y., Ooghe, I., Zhu, C., Depryck, K., Struyven, K., Pynoo, B. and Van Laer, H., 2017. Validation of a Conceptual Quality Framework for Online and Blended Learning with Success Factors and Indicators in Adult Education: A Qualitative Study. The Turkish Online Journal of Educational Technology, 16(3), pp.162-182. http://www.tojet.net/articles/v16i3/16315.pdf

Blieck, Y., Ooghe, I., Zhu, C., Depryck, K., Struyven, K., Pynoo, B. and Van Laer, H., 2018. Consensus about Success Factors and Indicators for Quality of Online and Blended Learning in Adult Education: a Delphi Study. Studies in Continuing Education. https://doi.org/10.1080/0158037X.2018.1457023

Bloxham, K.T., 2010. Using formative student feedback: A continuous quality improvement approach for online course development. All Graduate Theses and Dissertations. 801. https://digitalcommons.usu.edu/etd/801. [online] Utah State university. Available at: <http://digitalcommons.usu.edu/etd/801/> [Accessed 29 Jan. 2015].

Boelens, R., De Wever, B. and Voet, M., 2017. Four key challenges to the design of blended learning: A systematic literature review. Educational Research Review, 22, pp.1-18.

Cropanzano, R. 2009. Writing nonempirical articles for Journal of Management: General thoughts and suggestions. Journal of Management, 35, 1304-1311.

Creemers, B.P.M. and Kyriakides, L., 2010. Using the Dynamic Model to Develop an Evidence-Based and Theory-Driven Approach to School Improvement. Irish Educational Studies, 29(1), pp.5-23. 
Deepwell, F., 2007. Embedding Quality in e-learning Implementation through Evaluation. Educational Technology \& Society, 10(2), pp.34-43.

Deming, W.E., 1950. Elementary Principles of the Statistical Control of Quality. JUSE.

De Niel, H., Devlieger, M., Lambrechts, D., Mertens, E., Meulewaeter, M., Steverlycnk, C. and Van Nooten, M.-R. 2016. "OP(-)MAAT: Een onderzoek naar de behoeftedekkendheid en de behoeftegerichtheid van het NT2-aanbod in Vlaanderen", Vlaams Ministerie van Onderwijs en Vorming.

Ehlers, U.-D., 2004. Quality in e-learning from a learner's perspective. European Journal for Distance and Open Learning, [online] (2004(2)). Available at: <http://www.eurodl.org/index.php?p=archives\&year=2004\&halfyear=1\&article=101> [Accessed 8 Dec. 2014].

Ehlers, U.-D., 2007. Quality Literacy-Competencies for Quality Development in Education and e-Learning. Educational Technology \& Society, 10(2), pp.96-108.

Faddar, J., Vanhoof, J. and De Maeyer, S. 2017. "Instruments for school self-evaluation: lost in translation? A study on respondents' cognitive processing", Educational Assessment, Evaluation and Accountability, Vol. 29 No. 4, pp. 397420.

Gilson, L.L. and Goldberg, C.B., 2015. Editors' comment: So, what is a conceptual paper? [online] SAGE Publications Sage CA: Los Angeles, CA. Available at: <http://journals.sagepub.com/doi/full/10.1177/1059601115576425> [Accessed 23 Aug. 2017].

Hansson, H., 2008. E-learning quality. Aspects and criteria for evaluation of e-learning in higher education. (No. 2008:11 R). Luntmakargatan 13 Box 7851, 10399 Stockholm.

Graham, C.R. and Robison, R., 2007. Realizing the Transformational Potential of Blended Learning. In: A. Picciano and C. Dziuban, eds., Blended Learning: Research Perspectives. Needham, MA: United States of America: the Sloan Consortium., pp.83-111.

Hair, J., Hult, G.T., Ringle, C. and Sarstedt, M., 2014. A Primer on Partial Least Squares Structural Equation Modeling (PLSSEM). [online] Sage Publications Inc. Available at: <http://digitalcommons.kennesaw.edu/facbooks2014/39>.

Hansson, H., 2008. E-learning quality. Aspects and criteria for evaluation of e-learning in higher education. [online] Luntmakargatan 13 Box 7851, 10399 Stockholm. Available at: <http://www.divaportal.org/smash/record.jsf?pid=diva2:283764> [Accessed 11 Dec. 2014].

Harvey, L., 2003. Student Feedback [1]. Quality in Higher Education, 9(1), pp.3-20.

Herrington, J., McKenney, S., Reeves, T. and Oliver, R., 2007. Design-based research and doctoral students: Guidelines for preparing a dissertation proposal. [online] Available at: <http://researchrepository.murdoch.edu.au/6762/> [Accessed 10 May 2015].

Inglis, A., 2008. Approaches to the validation of quality frameworks for e-learning. Quality Assurance in Education, 16(4), pp.347-362.

Jara, M. and Mellar, H., 2009. Factors affecting quality enhancement procedures for e-learning courses. Quality Assurance in Education, 17(3), pp.220-232.

Jara, M. and Mellar, H., 2010. Quality enhancement for e-learning courses: The role of student feedback. Computers \& Education, 54(3), pp.709-714.

Jung, I., 2011. The Dimensions of E-Learning Quality: From the Learner's Perspective. Educational Technology Research and Development, 59(4), pp.445-464.

Jung, I., 2012. Asian learners' perception of quality in distance education and gender differences. The International Review of Research in Open and Distributed Learning, 13(2), pp.1-25.

Kipta, A.A. and Berge, Z.L., 2006. Process Transformations That Sustain Distance Training: A Blend of the Best of Common Maturity Models into a Framework. Distance Learning, 3(2), pp.13-21.

Lai, M.K. and Schildkamp, K., 2013. Data-based decision making: An overview. In: K. Schildkamp, M.K. Lai and L. Earl, eds., Data-based decision making in education: challenges and opportunities. Dordrecht: Springer, pp.9-21.

Leiber, T., Stensaker, B. and Harvey, L., 2015. Impact evaluation of quality assurance in higher education: methodology and causal designs. Quality in Higher Education, 21(3), pp.288-311.

Marshall, S., 2010. A Quality Framework for Continuous Improvement of e-Learning: The e-Learning Maturity Model. J. Distance Educ. 24, 143-166.

McLoughlin, C. and Lee, M.J., 2008. The Three P's of Pedagogy for the Networked Society: Personalization, Participation, and Productivity. International Journal of Teaching and Learning in Higher Education, 20(1), pp.10-27.

Moen, R.D. and Norman, C.L., 2010. Circling back. Quality Progress, 43(11), p.22.

Moore, J.C., 2005. The Sloan consortium quality framework and the five pillars. The Sloan Consortium. Retrieved July, 15, p.2007.

Moskal, P., Dziuban, C. and Hartman, J., 2013. Blended learning: A dangerous idea? The Internet and Higher Education, 18, pp.15-23.

Mutch, C., 2012. Complementary Evaluation: The Development of a Conceptual Framework to Integrate External and Internal Evaluation in the New Zealand School Context. Policy Futures in Education, 10(5), pp.569-586.

Nihuka, K.A. and Voogt, J., 2011. E-learning course design in teacher design teams: experiences in the Open University of Tanzania. International Journal of Learning Technology, 6(2), pp.107-124.

Nistor, N. and Neubauer, K., 2010. From participation to dropout: Quantitative participation patterns in online university courses. Computers \& Education, 55(2), pp.663-672. 
OECD, 2005. E-learning in Tertiary Education. [online] Paris: Organisation for Economic Co-operation and Development. Available at: <http://www.oecd-ilibrary.org/content/book/9789264009219-en> [Accessed 10 Dec. 2014].

Ossiannilsson, E. and Landgren, L., 2012. Quality in e-learning - a conceptual framework based on experiences from three international benchmarking projects. Journal of Computer Assisted Learning, 28(1), pp.42-51.

Ossiannilsson, E., Williams, K., Camilleri, A. and Brown, M., 2015. Quality models in online and open education around the globe. State of the art and recommendations. [online] Oslo: International Council for Open and Distance Education ICDE. Available at: <https://www.icde.org/assets/WHAT_WE_DO/icdequalitymodels22.pdf>.

Reeves, T.C., 2006. Design research from a technology perspective. In: J. van den Akker, K. Gravemeijer, S. McKenney \& N. Nieveen (Eds.), Educational design research. London: Routledge, pp.52-66.

Rovai, A.P., 2003. In search of higher persistence rates in distance education online programs. The Internet and Higher Education, 6(1), pp.1-16.

Schildkamp, K., Handelzalts, A., Poortman, C., Leusink, H., Meerdink, M., Smit, M., Ebbeler, J. and Hubers, M., 2014. De datateam methode. Een concrete aanpak voor onderwijsverbetering. [online] Antwerpen/Apeldoorn: Garant Uitgevers nv. Available at: <http://www.maklu.be/MakluEnGarant/Bookdetails.aspx?id=9789044131727> [Accessed 27 Sep. 2017].

Schildkamp, K. and Kuiper, W., 2010. Data-informed curriculum reform: Which data, what purposes, and promoting and hindering factors. Teaching and Teacher Education, 26(3), pp.482-496.

Schildkamp, K., Poortman, C., Luyten, H. and Ebbeler, J., 2016. Factors promoting and hindering data-based decision making in schools. School Effectiveness and School Improvement, pp.1-17.

Schildkamp, K., Poortman, C.L. and Handelzalts, A., 2015. Data teams for school improvement. School Effectiveness and School Improvement, pp.1-27.

Shea, P., 2007. Towards a conceptual framework for learning in blended environments. In: A.G. Picciano and C. Dzuiban, eds., Blended Learning: Research Perspectives. Needham, MA: The Sloan Consortium., pp.19-35.

Sonpal-Valias, N., 2009. MODULE 1 Outcome Evaluation: Definition and Overview. [online] Available at: <http://acds.ca/PDF/Outcome\%20Evaluations/MTD_Module_1_Outcome_Evaluation_Definition_and_Overview.pdf $>$ [Accessed 29 Jan. 2015].

Srikanthan, G. and Dalrymple, J., 2003. Developing alternative perspectives for quality in higher education. International Journal of Educational Management, 17(3), pp.126-136.

Srikanthan, G. and Dalrymple, J.F., 2002. Developing a Holistic Model for Quality in Higher Education. Quality in Higher Education, 8(3), pp.215-224.

Van Kemenade, E., 2017. Het Belang van de Context. Synaps, 39, pp.40-43.

Vanlommel, K., Vanhoof, J. and Petegem, P.V., 2016. Data use by teachers: the impact of motivation, decision-making style, supportive relationships and reflective capacity. Educational Studies, 42(1), pp.36-53.

Vlaams Parlement. Decreet betreffende het volwassenenonderwijs. 2007. Retrieved from http://dataonderwijs.vlaanderen.be/edulex/document.aspx?docid=13914

Williams, J., 2016. Quality assurance and quality enhancement: is there a relationship? Quality in Higher Education, 22(2), pp.97-102.

Williams, K., Kear, K., Rosewell, J., 2012. Quality Assessment for E-learning: a Benchmarking Approach (2nd ed.). European Association of Distance Teaching Universities (EADTU), Heerlen, The Netherlands.

Yin, R.K., 2009. Case study research: design and methods. 4th ed ed. Applied social research methods. Los Angeles, California: Sage Publications. 